\title{
Accurate Predictions of Postmortem Interval Using Linear Regression Analyses of Gene Meter Expression Data
}

Authors: M. Colby Hunter ${ }^{1}$, Alex E. Pozhitkov², and Peter A. Noble ${ }^{1,2,3}$

\section{Author Affiliations:}

1. Ph.D. Microbiology Program, Department of Biological Sciences, Alabama State University, Montgomery, Alabama, USA 36104

2. Department of Oral Health Sciences, University of Washington, Box 357444, Seattle, WA USA 98195.

3. Department of Periodontics, School of Dentistry, Box 355061, University of Washington, Seattle, Washington, USA 98195

*Correspondence to:

Peter A Noble

Email: panoble@washington.edu

Phone: 206-409-6664.

Other authors' emails:

MCH: cmooghww@gmail.com

AEP: pozhit@uw.edu

\section{Short title:}

PMI Prediction Using Gene Meter Analysis of Expression Data

\section{Keywords}

Postmortem transcriptome; postmortem gene expression; Gene meters; calibrated DNA microarrays, thanatotranscriptome; postmortem interval, forensic science. 


\section{Abstract (300 words)}

8 In criminal and civil investigations, postmortem interval is used as evidence to help sort

9 out circumstances at the time of human death. Many biological, chemical, and physical

10 indicators can be used to determine the postmortem interval - but most are not accurate.

11 Here, we sought to validate an experimental design to accurately predict the time of death

12 by analyzing the expression of hundreds of upregulated genes in two model organisms,

13 the zebrafish and mouse. In a previous study, the death of healthy adults was conducted

14 under strictly controlled conditions to minimize the effects of confounding factors such as

15 lifestyle and temperature. A total of 74,179 microarray probes were calibrated using the

16 Gene Meter approach and the transcriptional profiles of 1,063 genes that significantly

17 increased in abundance were assembled into a time series spanning from life to 48 or $96 \mathrm{~h}$

18 postmortem. In this study, the experimental design involved splitting the transcription

19 profiles into training and testing datasets, randomly selecting groups of profiles, determining the modeling parameters of the genes to postmortem time using over- and/or perfectly- defined linear regression analyses, and calculating the fit $\left(\mathrm{R}^{2}\right)$ and slope of

22 predicted versus actual postmortem times. This design was repeated several thousand to million times to find the top predictive groups of gene transcription profiles. A group of eleven zebrafish genes yielded $\mathrm{R}^{2}$ of 1 and a slope of 0.99 , while a group of seven mouse liver genes yielded a $\mathrm{R}^{2}$ of 0.98 and a slope of 0.97 , and seven mouse brain genes yielded a $\mathrm{R}^{2}$ of 0.95 and a slope of 0.87 . In all cases, groups of gene transcripts yielded better postmortem time predictions than individual gene transcripts. The significance of this study is two-fold: selected groups of gene transcripts provide accurate prediction of postmortem time, and the successfully validated experimental design can now be used to accurately predict postmortem time in cadavers. 


\section{Introduction} initiation of an official investigation to determine the cause of death. Its prediction is important to civil investigations such as those involving life insurance fraud because investigators need to determine if the person was alive or not when the policy was in effect [1]. The PMI is also important to criminal investigations, especially suspicious death cases where there are no witnesses, because it can help determine the time relationship between a potential suspect and the victim and eliminate people from a suspect list, which speeds up investigations. Accurate prediction of PMI is considered one of the most important and complex tasks performed by forensic investigators [2].

Several studies have suggested that RNA could be used to estimate PMI $[3,4,5,6,7]$. While most studies focused on the degradation of mRNA gene markers, some examined gene expression. The RNA degradation studies include: a model to predict PMI based on the degradation of Beta actin (Actb), Glyceraldehyde-3-phosphate dehydrogenase (Gapdh), Cyclophilin A (Ppia) and Signal recognition particle 72 (Srp72) genes in mouse muscle tissue samples [3], a model to predict PMI based on degradation of an amplified $A c t b$ gene and temperature in rat brain samples [4], and a study that predicted PMI based on the degradation of Gapdh, Actb and 18S rRNA genes in the spleens of rats [5]. The gene expression studies include: a study that found increased expression of myosin light chain 3 (Myl3), matrix metalloprotease 9 (Mmp9) and vascular endothelial growth factor A (Vegfa) genes in human body fluids after $12 \mathrm{~h}$ postmortem [6], a study that found increased expression of Fas Ligand (Fasl) and 'phosphatase and tensin homologue deleted on chromosome 10' (Pten) genes with postmortem time in rats [7], and a study that found individual gene transcripts did not increase using PCR-based gene expression arrays of frozen human brain cadaver samples [8]. Common to these studies is the requirement: (i) to amplify cDNA by polymerase chain reaction (PCR) and (ii) to normalize the data with a control in order to facilitate sample comparisons. These requirements introduce methodological biases that could significantly affect interpretation of the data $[9,10,11]$. An approach that minimizes or eliminates these biases is highly desirable because it might lead to better PMI predictions. 
Since conventional DNA microarray approaches yield noisy data [12], in 2011 we developed the "Gene Meter" approach that precisely determines specific gene abundances in biological samples and minimizes noise in the microarray signal $[13,14,16]$. The reason this approach is precise is because the behavior of every microarray probe is determined by calibration - which is analogous to calibrating a $\mathrm{pH}$ meter with buffers. Without calibration, the precision and accuracy of a meter is not known, nor can one know how well the experimental data fits to the calibration (i.e., $R^{2}$ ). The advantages of the Gene Meter approach over conventional DNA microarray approaches is that the calibration takes into consideration the non-linearity of the microarray signal and calibrated probes do not require normalization to compare biological samples. Moreover, PCR amplification is not required. We recognize that next-generation-sequencing (NGS) approaches could have been used to monitor gene expression in this study. However, the same problems of normalization and reproducibility are pertinent to NGS technology $[15,16]$. Moreover, a recent publication, by a group from National Institute of Standards and Technology, used the same dilution series approach (as we did) to evaluate and calibrate RNASeq [17]. They found RNASeq comparable to microarrays, in terms of target quantification, but not superior, as it may be perceived by the community. Hence, the Gene Meter approach is currently the most advantageous high throughput methodology to study postmortem gene expression and might have utility for determining the PMI.

The Gene Meter approach has been used to examine thousands of postmortem gene transcription profiles from 44 zebrafish (Danio rerio) and 20 house mice (Mus musculus) [18]. Many genes were found to significantly increase in abundance relative to live controls. Given that each sampling time was replicated two or three times, we conjectured that the datasets could be used to assess the feasibility for predicting PMIs from gene expression data. Although many approaches are available to determine PMI (see Discussion), an approach that accurately determines the time of death is highly desired and it is the goal of our study to determine if specific gene transcripts or groups of gene transcripts could accurately predict postmortem time. Zebrafish and mice are ideal for testing experimental designs because the precise time of human deaths is often not known, and other variables such as lifestyle, temperature, and health condition are 
also often not known or sufficiently controlled in human studies. Given that these variables could have confounding effects on the interpretation of gene expression data in human studies, testing experimental designs under controlled conditions using model organisms is ideal. In our study, the timing of death and health of the zebrafish and mice are known, which enables the testing of different experimental designs to provide "proof of principle". Our intent is to use the best design to determine PMI of cadavers in future studies.

The objectives of our study are twofold: (1) to identify specific gene transcripts or groups of gene transcripts that accurately predict the PMI in the zebrafish and mouse, and (2) to design and evaluate a robust experimental approach that could later be implemented to predict PMI in cadavers.

\section{Materials and methods}

Although the details of zebrafish and mouse processing, the extraction of RNA, and microarray calibrations are presented in a previous study [18], we have provided relevant experimental protocols to aid readers in the interpretation of the results of this study.

Zebrafish processing. The 44 zebrafish were maintained under standard conditions in flow-through aquaria with a water temperature of $28^{\circ} \mathrm{C}$. Prior to sacrifice, the zebrafish were placed into $1 \mathrm{~L}$ of water of the same temperature as the aquaria. At zero time, four fish were extracted and snap frozen in liquid nitrogen. These live controls were then placed at $-80^{\circ} \mathrm{C}$. To synchronize the time of death, the remaining 40 fish were put into a small container with a bottom made of mesh and placed into an $8 \mathrm{~L}$ container of ice water for 5 mins. The small container with the mesh bottom was placed into the flow-through aquarium with a water temperature of $28^{\circ} \mathrm{C}$ for the duration of each individual's designated postmortem time. The postmortem sampling times used for the zebrafish were: 0, $15 \mathrm{~min}, 30 \mathrm{~min}, 1$, 4, 8, 12, 24, 48 and $96 \mathrm{~h}$. At each sampling time, 4 individuals were taken out of the small container in the flow-through aquarium, snap frozen in liquid nitrogen and then stored at $-80^{\circ} \mathrm{C}$. One zebrafish sample was not available for use (it was accidentally flushed down the sink) however this was taken into account for calculation of extraction volumes. 
Mouse processing. Twenty C57BL/6JRj male mice of the same age (5 months) and similar weight were used. Prior to sacrifice, the mice had ad libitum access to food and water and were maintained at room temperature. At zero time, the mice were sacrificed by cervical dislocation and each mouse was placed in a unique plastic bag with pores to permit the transfer of gases. The mice were kept at room temperature for the designated postmortem sampling times. The sampling times used were: “zero" time, $30 \mathrm{~min}, 1,6$, 12, 24 and $48 \mathrm{~h}$. At each sampling time, a brain and two liver samples were obtained from each of three mice, except for the $48 \mathrm{~h}$ sampling where only two mice were sampled. The samples were immediately snap frozen in liquid nitrogen and placed at $80^{\circ} \mathrm{C}$.

RNA Processing and Labeling. Gene expression samples for each PMI were done in duplicate for zebrafish and in triplicate for mice (except for the $48 \mathrm{~h}$ PMI sample that was duplicated). The zebrafish samples were homogenized with a TissueLyzer (Qiagen) with $20 \mathrm{ml}$ of Trizol. The mouse brain and liver samples ( 100 mg) were homogenized in 1 $\mathrm{ml}$ of Trizol. One $\mathrm{ml}$ of the homogenate was placed into a centrifuge tube containing 200 $\mu 1$ of chloroform. The tube was vortexed and placed at $25^{\circ} \mathrm{C}$ for three min. Following centrifugation for $15 \mathrm{~min}$ at $12000 \mathrm{RPM}$, the supernatant was placed into a new centrifuge tube containing an equal volume of $70 \%$ ethanol. Purification of the RNA was accomplished using the PureLink RNA Mini Kit (Life Technologies, USA). The purified RNA was labeled using the One-Color Microarray-based Gene Expression Analysis (Quick Amp Labeling). The labeled RNA was hybridized to the DNA microarrays using the Tecan HS Pro Hybridization kit (Agilent Technologies). The zebrafish RNA was hybridized to the Zebrafish (v2) Gene Expression Microarray (Design ID 019161) and the mouse RNA was hybridized to the SurePrint G3 Mouse GE 8x60K Microarray Design ID 028005 (Agilent Technologies) following the manufacturer's recommended protocols. The microarrays were loaded with $1.65 \mu \mathrm{g}$ of labeled cRNA for each postmortem time and sample.

Microarray calibration. Oligonucleotide (60 nt) probes on the zebrafish and mouse microarrays were calibrated using pooled labeled cRNA of all zebrafish and all mouse postmortem samples, respectively. The dilution series for the Zebrafish array was created from one stock making up the following concentrations of labeled cRNA: 0.41, 0.83, 
$1.66,1.66,1.66,3.29,6.60$, and $8.26 \mu \mathrm{g}$. The dilution series for the Mouse arrays was

155 created from one stock making the following concentrations of labeled cRNA: 0.17, 0.33,

$1560.66,1.32,2.64,5.28,7.92$, and $10.40 \mu \mathrm{g}$. Calibration involved plotting the signal

157 intensities of the probes against a dilution factor and determining the isotherm model

158 (e.g., Freundlich and/or Langmuir) that best fit the relationship between signal intensities

159 and gene abundances.

160 Consider zebrafish gene transcripts targeted by A_15_P110618. It was found that the

161 measurements for this probe best fit the Freundlich model with $\mathrm{R}^{2}=0.99$. The equation

162 for this probe is the following:

$163 S I=\exp (7.1081) x^{0.67632}$

164 where SI is the observed average signal intensity for the dilution $x$. The transcript

165 abundance $G$ was calculated by inverting this equation. For each probe signal intensity at

166 postmortem time, $S I_{t}$, the gene abundance $G=\left(S I_{t} / \exp (7.1081)\right)^{\wedge}(1 / 0.67632)$.

167 Specifically, consider two biological replicates of $15 \mathrm{~min}$ postmortem zebrafish, the

168 signal intensities of the probe A_15_P110618 are 770.5 and 576, which translates into the

169 abundances 0.50 and 0.33 arbitrary units (a.u.) respectively. Further details of the

170 calibration protocols used to calculate RNA transcript relative abundances are provided

171 in references 13,14 .

172 Statistical analyses. Abundance levels were log-transformed for analysis to stabilize the

173 variance. A one-sided Dunnett's T-statistic was applied to test for increase at one or more

174 postmortem times compared to live control (fish) or time 0 (mouse). A bootstrap

175 procedure with 109 simulations was used to determine the critical value for the Dunnett's

176 statistics in order to accommodate departures from parametric assumptions and to

177 account for multiplicity of testing. The transcript profile for each gene were centered by

178 subtracting the mean values at each postmortem time point to create "null" profiles.

179 Bootstrap samples of the null profiles were generated to determine the 95th percentile of

180 the maximum (over all genes) of the Dunnett's statistics. A gene was considered to have

181 a significantly increased abundance when one or more points had Dunnett's $\mathrm{T}$ values

182 larger than the 95th percentile. These genes were retained for further analyses. 
The transcriptional profiles that significantly increased in abundance relative to controls are publically available for download as electronic supplementary files. There are 3 files, one for the zebrafish, and two for the mouse (brain and liver samples were separated): zebrafish_calib_probe_abundance.txt, mice_liver_probe_log10_abundance.txt, and mice_brain_probe_log10_abundance.txt, respectively. Each file has the following four columns: Agilent Probe Identification Tag, sample time, sample number and log 10 concentration.

The software for calculating the numerical solution of the over- and perfectly-defined linear regressions was coded in $\mathrm{C}++$ and has been used in previous studies $[19,20]$. The $\mathrm{C}++$ code allowed us to train and test thousands to millions of regression models. A description of the analytical approach can be found in the original publication [20]. Briefly, the abundances of each gene transcript in a gene set was numerically solved in terms of predicting the postmortem times with modeling parameters (i.e. coefficients). A version of the $\mathrm{C}++$ source code is available at http://peteranoble/software under the heading: "Determine the coefficients of an equation using matrix algebra". The web page includes a Readme and example files to help users implement the code. To aid readers in understanding the linear matrix algebra used in the study, we have provided a primer in the Supplemental Information section. The postmortem time was predicted from the sum of the product of the gene abundances multiplied by the coefficients for each gene transcript. Comparing the predicted to actual PMIs with the testing dataset was used to assess the quality of the prediction (the fit (i.e., $\mathrm{R}^{2}$ ) and slope.

Gene annotation. The genes were annotated by performing BLASTN searches using the NCBI databases. Genes that had a bit score of greater than or equal to 100 were annotated.

Experimental design. Three different datasets were used in this study: the whole zebrafish transcriptome, the mouse brain transcriptome, and the mouse liver transcriptome. The datasets were split into training and testing data. The training data was used to build the regression equations and the testing data was used to validate the equations. Three different experimental designs were tested. 
1. Simple linear regressions using individual genes. We examined if simple linear regressions $\left(P M I_{\text {predict }}=m^{*}\right.$ transcript abundance $\left.+b\right)$ of individual gene transcripts could be used to predict PMIs. The values of $m$ and $b$ were determined using the training dataset. The performance of the regression was assessed using the $\mathrm{R}^{2}$ of the predicted versus actual PMIs with both training and testing datasets.

2. Over-defined linear regressions using top performing genes from Experimental Design 1. An over-defined linear regression is used when the data consisted of more rows (postmortem times) than columns (gene transcripts). The top three individual gene transcripts in Experimental Design 1 were combined and trained to predict PMIs using an over-defined linear regression model. The performance of the model was assessed using the $\mathrm{R}^{2}$ of the predicted versus actual PMIs of both training and testing datasets.

3. Perfectly defined linear regressions using randomly selected gene transcript sets. A perfectly-defined linear regression is used for data consisting of equal number of rows (postmortem times) and columns (gene transcripts). A random number generator was used to select sets of genes from the datasets in order to find the top PMI predictors. The analysis yields a set of coefficients (i.e., $m$ 's), one coefficient for each gene transcript in a set. The coefficients were used to predict the PMIs of a gene set. The $\mathrm{R}^{2}$ and slope of the predicted versus actual PMIs were determined using the testing data. Since the mouse samples consisted of three data points for each sample time (except $48 \mathrm{~h}$ sample that contained two points), one datum point was used for training, one datum point was used to testing, and the third datum point was used for validation. The validation data was not used in the training or selection. The procedure of selecting the gene transcript sets from the training set, determining the coefficients, and testing the coefficients was repeated at least 50,000 or more times and the gene transcript sets generating the best fit $\left(\mathrm{R}^{2}\right)$ and slopes were identified (Fig 1). 
Repeat $10000+$ times

\begin{tabular}{|c|c|c|c|c|}
\hline $\begin{array}{l}\text { Training } \\
\text { dataset }\end{array}$ & \multirow{2}{*}{$\begin{array}{l}\text { Random } \\
\text { selection of } \\
\text { probeset } \\
\text { ( } \rho \text { probes) }\end{array}$} & \multirow{2}{*}{\begin{tabular}{|l|}
$\begin{array}{c}\text { LS regression } \\
\text { (Coefficient } \\
\text { determination) }\end{array}$ \\
$\quad$ Predict PMI \\
\end{tabular}} & \multirow{2}{*}{$\begin{array}{l}\text { Calculate } \mathrm{R}^{2} \\
\text { and slope of } \\
\text { predicted vs } \\
\text { actual PMI }\end{array}$} & \multirow{2}{*}{$\begin{array}{c}\text { Retain } \\
\text { top } 3 \\
\text { probe- } \\
\text { sets }\end{array}$} \\
\hline $\begin{array}{l}\text { Testing } \\
\text { dataset }\end{array}$ & & & & \\
\hline
\end{tabular}

Fig 1. Cartoon of experimental design for three different datasets. Bold box was repeated $10,000+$ times. The top 3 probe datasets were determined by the $R^{2}$ between predicted versus actual PMI and the slope closest to one using the test dataset. If $X=$ 'zebrafish' then $n=548, t=11, p=11$; if $X=$ 'mouse brain' then $n=478, t=7, p=7$; if $X=$ 'mouse liver' then $n=36$, $t=7, p=7$.

\section{Results}

The 36,811 probes of the zebrafish and 37,368 probes of the mouse were calibrated. Of these, the transcriptional profiles of 548 zebrafish genes and 515 mouse genes were found to significantly increase (see Supplementary files S1, S2, S3). Of the 515 genes, 36 were from the liver, and 478 genes were from the brain. It is important to note that each datum point in a zebrafish transcriptional profile represents the mRNA obtained from two zebrafish and each datum point in a mouse profile represents the mRNA obtained from one mouse. In other words, each datum point represents a true biological replicate. Duplicate samples were collected for each postmortem time for the zebrafish profiles, and triplicate samples were collected for the mouse (with exception of the $48 \mathrm{~h}$ postmortem sample which was duplicated) at each postmortem time.

\section{Predicting PMI with 1 or 3 gene transcripts.}

The ability of individual gene transcripts to accurately predict PMIs was assessed using the simple linear regression:

$P M I_{\text {predict }}=m \log _{2} G+b$, with $m$ as the slope (i.e., the coefficient), $G$ is the individual gene transcript abundance, and $b$ is the intercept.

For the zebrafish, one of the duplicates (at each postmortem time) was used to determine the linear regression equation (i.e., $m$ and $b$ ) and the other one was used to test the regression equation. For the mouse, one of the triplicates at each postmortem time was used to determine the linear equation and the remaining data ( 2 data points) were used to 
test the regression equation. The three gene transcripts of the zebrafish, mouse brain, and mouse liver with the highest fits $\left(\mathrm{R}^{2}\right)$ between predicted and actual PMIs are shown in Table 1.

Table 1. Top three fits $\left(\mathrm{R}^{2}\right)$ of predicted and actual PMIs by organism/organ based on the training and testing datasets of individual probes (probe names were designated by Agilent) targeting specific transcripts. Corresponding gene names and functions are shown. Whole, RNA was extracted from whole organisms; Brain, RNA extracted from mouse brains; Liver, RNA extracted from mouse livers.

\begin{tabular}{|c|c|c|c|c|}
\hline $\begin{array}{c}\text { Organism/ } \\
\text { Organ }\end{array}$ & $\begin{array}{c}\text { Oligonucleotide } \\
\text { Probe Name }\end{array}$ & $\mathbf{R}^{2}$ & Number of data points & Gene Name and Function \\
\hline \multicolumn{5}{|l|}{ Zebrafish } \\
\hline Whole & $\begin{array}{l}\text { A_15_P121158 } \\
\text { A_15_P295031 } \\
\text { A_15_P407295 }\end{array}$ & $\begin{array}{l}0.94 \\
0.84 \\
0.82 \\
\end{array}$ & $\begin{array}{l}11 \text { duplicates } \\
11 \text { duplicates } \\
11 \text { duplicates } \\
\end{array}$ & $\begin{array}{l}\text { Non-coding } \\
\text { Non-coding } \\
\text { Non-coding } \\
\end{array}$ \\
\hline \multicolumn{5}{|l|}{ Mouse } \\
\hline Brain & $\begin{array}{l}\text { A_66_P130916 } \\
\text { A_55_P2127959 } \\
\text { A_55_P2216536 }\end{array}$ & $\begin{array}{l}0.67 \\
0.61 \\
0.60\end{array}$ & $\begin{array}{l}6 \text { triplicates and } 1 \text { duplicate } \\
6 \text { triplicates and } 1 \text { duplicate } \\
6 \text { triplicates and } 1 \text { duplicate }\end{array}$ & $\begin{array}{l}\text { Histocompatibility } 2, \mathrm{O} \text { region beta } \\
\text { locus } \\
\text { Zinc finger protein } 36, \mathrm{C} 3 \mathrm{H} \text { type-like } 3 \\
\text { E3 ubiquitin-protein ligase }\end{array}$ \\
\hline Liver & $\begin{array}{l}\text { A_55_P2006861 } \\
\text { A_30_P01018537 } \\
\text { A_51_P318381 }\end{array}$ & $\begin{array}{l}0.94 \\
0.91 \\
0.90\end{array}$ & $\begin{array}{l}6 \text { triplicates and } 1 \text { duplicate } \\
6 \text { triplicates and } 1 \text { duplicate } \\
6 \text { triplicates and } 1 \text { duplicate }\end{array}$ & $\begin{array}{l}\text { Triple functional domain protein } \\
\text { Prokineticin-2 isoform } 1 \text { precursor } \\
\text { Placenta growth factor isoform } 1 \\
\text { precursor }\end{array}$ \\
\hline
\end{tabular}

For the zebrafish, the gene transcript targeted by probe A_15_P121158 yielded a fit (combined training and testing data) of $\mathrm{R}^{2}=0.94$, while the other gene transcripts yielded moderate fits $\left(\mathrm{R}^{2}<0.90\right)$. The top predictors of PMIs for the mouse brain samples yielded weak $\mathrm{R}^{2}$-values $(0.61$ to 0.67$)$, and the top predictors for the mouse liver samples yielded reasonable $\mathrm{R}^{2}$-values $(0.90$ to 0.94$)$ (Table 1$)$ suggesting that the liver was more suitable for predicting PMI than the brain.

284 if a combination of the top gene transcripts would improve upon PMI predictions. Using an over-defined linear regression:

$P M I_{\text {predict }}=\sum_{i=1}^{3} m_{i} \log _{2} G_{i}$ and one of the duplicate/triplicate samples from each postmortem time as the training data, we determined the coefficient for each gene transcript and tested the regression equation using the remaining test data. For the zebrafish, the derived coefficients for genes targeted by probes A_15_P295031, A_15_P121158, and A_15_P407295 were 
$-162.97,22.44$, and 35.10, respectively. Using the gene transcript abundances for these probes at $48 \mathrm{~h}$ postmortem (-0.33 a.u., -0.89 a.u., and -0.25 a.u., respectively) and the equation above, the predicted PMI is $\sim 25.3 \mathrm{~h}$. For the mouse brain gene transcripts targeted by probes A_66_P130916, A_55_P2127959, and A_55_P2216536, the derived coefficients were $3.70,-3.57$, and 45.25 , respectively. Using the gene transcript abundances for these probes at $48 \mathrm{~h}$ postmortem (1.21 a.u., 0.36 a.u., and 0.80 a.u., respectively) and the equation above, the predicted PMI is $\sim 39.2 \mathrm{~h}$. For the mouse liver gene transcripts, the derived coefficients targeted by probes A_51_P318381, A_30_P01018537, and A_55_P2006861 were -3.75, 36.21, and -13.93, respectively. Using the gene transcript abundances for these probes at $48 \mathrm{~h}$ postmortem (1.04 a.u., 1.65 a.u., and 0.48 a.u., respectively) and the equation above, the predicted PMI is $\sim 49.3 \mathrm{~h}$. The fits $\left(\mathrm{R}^{2}\right)$ of the predicted versus actual PMIs for the zebrafish, the mouse brain and mouse liver were $0.74,0.64$, and 0.86 , respectively.

While some of the individual gene transcript abundances yielded reasonable PMI predictions using simple linear equations (Table 1), combining the individual gene transcript abundances and using an over-defined linear regression did not significantly improve upon PMI predictions based on individual genes.

These experiments showed that neither simple linear regression equations derived from the individual gene transcripts, nor over-defined linear regressions derived from the top three individual gene transcripts satisfactorily predicted PMIs.

\section{Predicting PMI with many genes}

The algebraic constraint to predict PMIs using perfectly defined linear regressions is that the number of gene transcripts used for the regression has to equal the number of postmortem sampling times. The zebrafish was sampled 11 times and the mouse was sampled 7 times, therefore 11 and 7 genes could be used for the regressions, respectively. The regression equation for the zebrafish was:

$$
P M I_{\text {predict }}=\sum^{11}{ }_{i=1} m_{i} \log _{2} G_{i}
$$


The regression equation for the mouse was:

$P M I_{\text {predict }}=\sum_{i=1}^{7} m_{i} \log _{2} G_{i}$

The procedure to find gene transcript sets that provide the best PMI predictions included: assigning randomly-selected genes to gene transcript sets, determining the coefficients of the gene transcripts in the set using a defined least squared linear regression, and assessing the regression model with gene transcript sets in the test data. We speculated that if this process was repeated thousands to millions of times, groups of gene transcripts could be identified that accurately predict PMIs with high $\mathrm{R}^{2}=>0.95$ and slopes of 0.95 to 1.05 .

The number of upregulated genes in the zebrafish, mouse brain, and mouse liver transcriptome datasets is relevant to determining the optimal gene transcript set for PMI predictions because of the magnitude of possible combinations to be explored. For example, there are $2.85 \times 10^{22}$ combinations of 11 gene transcripts for the zebrafish dataset $(n=548), 1.08 \times 10^{15}$ combinations of 7 gene transcripts for the mouse brain dataset $(n=478)$ and $8.35 \times 10^{6}$ possible combinations of 7 gene transcripts for the mouse liver dataset $(n=36)$. Therefore, for some transcriptome datasets (i.e., zebrafish and mouse brain), the determination of the best gene transcript set to accurately predict PMI was constrained by the number of possible combinations explored in reasonable computer time.

\section{Validation of PMI prediction}

After training 50,000 random selections, about 95\% $(n=47,582)$ of the selected gene transcript sets yielded $\mathrm{R}^{2}$ and slopes of 1 with the training datasets. The remaining selections $(n=2,418)$ did not yield $\mathrm{R}^{2}$ and/or slopes of 1 because the equations could not be resolved, or else the fits and/or slopes were $<1$. The $\mathrm{R}^{2}$ and slope of the predicted versus actual PMIs based on the testing data were used to identify the top gene sets. 
The top three gene transcript sets with the highest $\mathrm{R}^{2}$ and slopes closest to one are shown in Fig 2. The gene transcript set used in Panel A had smaller confidence intervals than those found in Panels B and C. At the 99\% confidence level, the predicted PMIs for the gene set in Panel A ranged from 7 to $11 \mathrm{~h}$ for the actual PMI of $9 \mathrm{~h}$, from 8 to $16 \mathrm{~h}$ for the actual PMI of $12 \mathrm{~h}$, from 21 to $27 \mathrm{~h}$ for the actual PMI of $24 \mathrm{~h}$, from 46 to $50 \mathrm{~h}$ for the actual PMI of $48 \mathrm{~h}$, from $96 \mathrm{~h}$ for the actual PMI of $96 \mathrm{~h}$. These results suggest that PMIs could be accurately predicted using zebrafish gene sets and the derived coefficients.
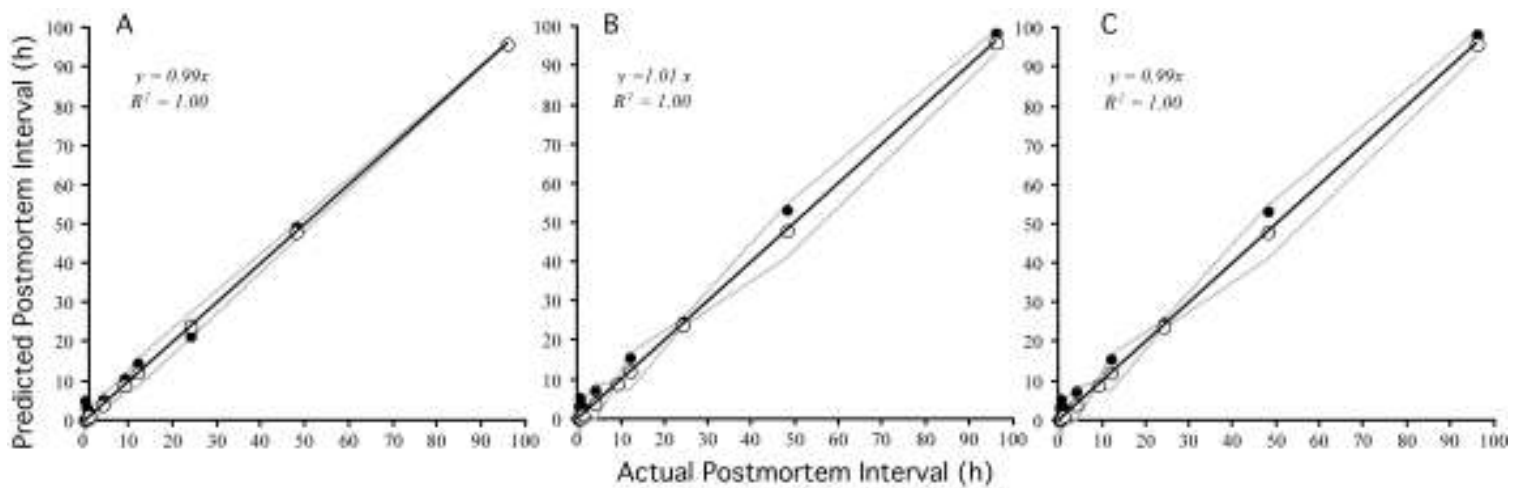

Fig 2. Predicted versus actual PMIs determined for the zebrafish by three equations representing different gene transcript sets. $\mathbf{R}^{2}$ and slopes are based on both training and testing datasets. Gray line represents $\mathbf{9 9 \%}$ confidence limits of the linear regression. Open circles, training data; closed circles, testing data. See Table 1 for information on the genes and annotations.

The gene transcription profiles of the 11 genes used in Fig 2, Panel A are shown in Fig 3.

Note that the gene transcript abundances of the duplicate samples used for training and testing are similar at all sampling times. These results show the high precision of the Gene Meter approach since each datum point represents different zebrafish. Note that each gene has a different postmortem transcriptional profile. 


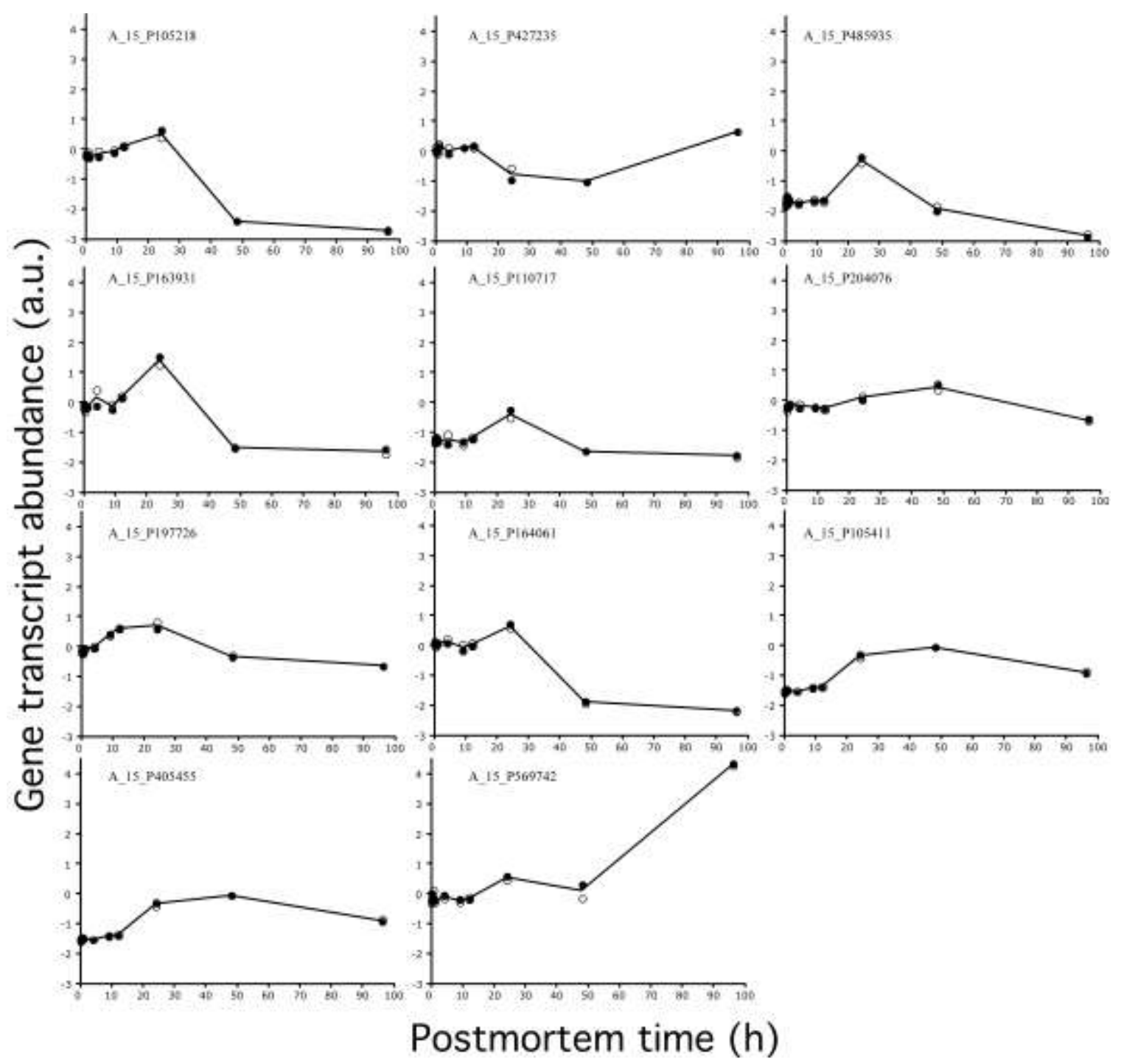

Fig 3. Zebrafish transcriptional profiles contributing to Fig 2, Panel A. Open circles, training data; closed circles, testing data; black line, average. See Table 2 for information on the equations and probe annotations.

Table 2 shows the probe labels for the gene transcript sets used in Fig 2 Panels A to C and their corresponding coefficients derived from the training dataset. Note that only some genes could be annotated using NCBI. We assumed that genes not annotated represent non-coding mRNA. The PMIs in Panel A to $\mathrm{C}$ could be predicted by adding the products of the $\log _{2}$ abundance of each gene to its corresponding coefficient. For example, the equation for Table 2 Panel A is:

$\mathrm{PMI}=-13.39 \mathrm{P}_{1}-5.72 \mathrm{P}_{2}+5.72 \mathrm{P}_{3}+12.82 \mathrm{P}_{4}-7.07 \mathrm{P}_{5}-10.26 \mathrm{P}_{6}+13.13 \mathrm{P}_{7}-16.00 \mathrm{P}_{8}+$ $5.44 \mathrm{P}_{9}-4.39 \mathrm{P}_{10}+11.94 \mathrm{P}_{11}$ 
where $P_{i}$ are the gene abundances represented by the probes A_15_P105218 (0.39 a.u.), A_15_P427235 (-0.54 a.u.), A_15_P485935 (-0.39 a.u.), A_15_P163931 (1.27 a.u.), A_15_P110717 (-0.53 a.u.), A_15_P204076 (0.16 a.u.), A_15_P197726 (0.82 a.u.), A_15_P164061 (0.58 a.u.), A_15_P105411 (-0.40 a.u.), A_15_P405455 (-1.13 a.u.), A_15_P569742 (0.46 a.u.). In this example, the predicted PMI is $~ 24$ h. Based on Figure 2 panel A, the $99 \%$ confidence interval is between 20.9 and $27.1 \mathrm{~h}$.

Table 2. Zebrafish genes used to predict PMI by Panel. The gene annotations of the probes were determined using NCBI with a 100 bit minimum.

\begin{tabular}{|c|l|c|c|l|}
\hline Panel & Probe Label & Coefficient & Gene & Gene Name \\
\hline A & A_15_P105218 & -13.39 & Gpr98 & G-protein coupled receptor 98 precursor \\
& A_15_P427235 & -5.72 & & Noncoding \\
& A_15_P485935 & 5.72 & & Noncoding \\
& A_15_P163931 & 12.82 & Moxd1 & DBH-like monooxygenase protein 1 homolog precursor \\
& A_15_P110717 & -7.07 & Svep1 & Sushi von Willebrand factor type A, EGF and pentraxin \\
& A_15_P204076 & -10.26 & Pde4b & 5'-cyclic-AMP and -GMP phosphodiesterase 11 \\
& A_15_P197726 & 13.13 & Plek2 & Pleckstrin-2 \\
& A_15_P164061 & -16.00 & Rassf6 & Ras association domain-containing protein 6 \\
& A_15_P105411 & 5.44 & Grm7 & Metabotropic glutamate receptor 7-like \\
& A_15_P405455 & -4.39 & & Noncoding \\
& A_15_P569742 & 11.94 & Trim25 & E3 ubiquitin/ISG15 ligase TRIM25-like \\
& & & & \\
& A_15_P104895 & 19.66 & & Noncoding \\
& A_15_P522677 & -26.62 & & Noncoding \\
& A_15_P105411 & 13.32 & Grm7 & Metabotropic glutamate receptor 7-like \\
& A_15_P119193 & 15.64 & & Noncoding \\
& A_15_P401770 & 5.89 & Lrrc59 & Leucine-rich repeat-containing protein 1 \\
& A_15_P104490 & -27.55 & Wif1 & Wnt inhibitory factor 1 precursor \\
& A_15_P177366 & -3.88 & Bmpr2 & Bone morphogenetic protein receptor, type II a \\
& A_15_P586597 & -7.64 & & Noncoding \\
& A_15_P168556 & 6.77 & Sema6d & Semaphorin-6D isoform X1 \\
& A_15_P105618 & 17.47 & Gpr143 & G-protein coupled receptor 143 \\
& A_15_P171831 & 6.86 & Il20 & Interleukin-20 isoform X1 \\
& & & & \\
& A_15_P569842 & 3.20 & Myo3a & Myosin-IIIa \\
& A_15_P176341 & 2.03 & Prrt4 & Proline-rich transmembrane protein 4 \\
& A_15_P107601 & 8.59 & Atf3 & Cyclic AMP-dependent transcription factor ATF-3 \\
A_15_P168526 & -5.03 & Pglyrp1 & Peptidoglycan recognition protein 1 \\
& A_15_P328806 & -5.37 & Kdm5b & Lysine-specific demethylase 5B \\
& A_15_P309786 & 2.33 & FimC & Integumentary mucin C.1-like \\
\hline A_15_P120901 & 0.31 & Gnail & Guanine nucleotide-binding protein G(i) subunit alpha-1
\end{tabular}


393

394

395

396

397

398

399

400

401

402

403

404

405

406

407

408

409

410

411

412

413

414

415

416

\begin{tabular}{l|c|c|l} 
A_15_P165836 & 6.98 & C3arl & C3a anaphylatoxin chemotactic receptor-like \\
A_15_P576307 & 1.91 & & Noncoding \\
A_15_P110820 & -34.27 & Gucyla3 & Guanylate cyclase soluble subunit alpha-3 \\
A_15_P105618 & 32.01 & Gprl43 & G-protein coupled receptor 143
\end{tabular}

Mouse

After training 50,000 random selections (each selection consisted of 7 genes), about 96\% $(n=47,847)$ of the selected gene sets yielded $\mathrm{R}^{2}$ and slopes of 1 . The remaining selections were not used for testing because the equations ( $n=2,153$ selections) could not be resolved, or they had fits and/or slopes that were $<1$ ( $n=25$ selections). The $\mathrm{R}^{2}$ and slope of predicted versus actual PMIs of the testing dataset were used to identify the top performing gene sets.

The top selected gene transcript sets for the mouse liver and brain are shown in Fig 4. As indicated by the $\mathrm{R}^{2}$, slopes, and size of the $99 \%$ confidence intervals, gene transcript sets from the liver were better at predicting PMIs than those from the brain.

For the liver (Fig. 4, left panel), the $\mathrm{R}^{2} \mathrm{~s}$ of the testing and validation data (not used in training) were 0.99 and 0.97 , respectively. The combined $\mathrm{R}^{2}$ of the training, testing and validation data was 0.98 with a slope of 0.97 . For the first brain sample (Fig. 4, middle panel), the $\mathrm{R}^{2}$ s of the testing and validation data were 0.95 and 0.87 , respectively. The combined $\mathrm{R}^{2}$ of the training, testing and validation data was 0.94 with a slope of 0.85 . For the second brain sample (Fig. 4, right panel), the $\mathrm{R}^{2} \mathrm{~s}$ of the testing and validation data were 0.95 and 0.92 , respectively. The combined $\mathrm{R}^{2}$ of the training, testing and validation data was 0.92 with a slope of 0.86 .

The mouse genes used in the gene transcript sets, their coefficients, and annotations are shown in Table 3 and the transcriptional gene profiles for the mouse liver samples are shown in Fig 5. Note that the high similarity in the gene transcript abundance between the data used for training and testing of the selected genes. In most cases (but not all), the samples (represented by dots) are located on top of one another. 


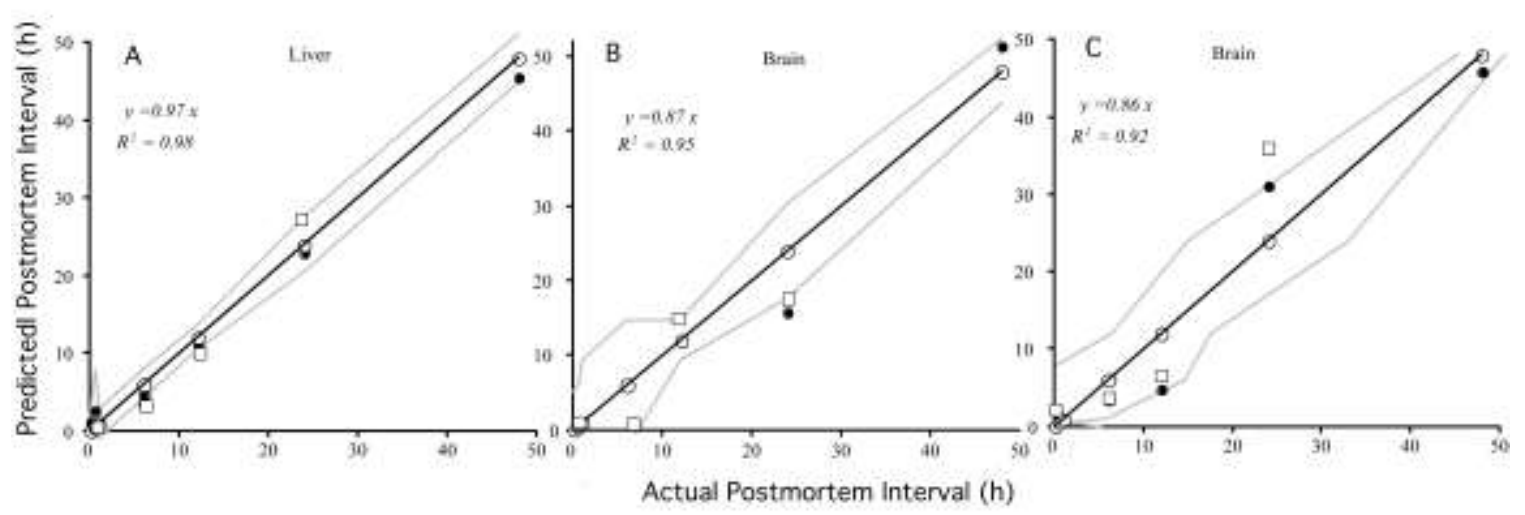

417

Fig 4. Predicted versus actual PMI determined for the mouse for three different equations as represented by the panels. $R^{2}$ and slopes are based on both training and testing datasets. Gray line represents $99 \%$ confidence limits of the linear regression. Open circles, training data; closed circles, testing data; open squares, validation data (not used in training or selection). See Table 3 for information on the equations and probes.

The poor predictability of the brain gene transcript sets (i.e., $\left.\mathrm{R}^{2}<0.95\right)$ could be attributed to the low number of repeated selections of gene transcript sets and the variability in gene abundances between the training and testing datasets. We repeated the analysis of the brain samples an additional 1,000,000 times, which resulted in some improvement. The best fit and slope for 50,000 gene transcript set selections was $\mathrm{R}^{2}=0.83$ and $m=0.77$ (not shown). The best fit and slope for $1,000,000$ selections was $\mathrm{R}^{2}=0.95$ and $m=0.87$ (Fig 4, Panel B) with the second best being $\mathrm{R}^{2}=0.92$ and $m=0.86$ (Fig 4, Panel C). Hence, the number of combination of gene transcript sets examined is important for selecting the best ones. It is important to emphasize that the computation time for running $1,000,000$ selections was approximately 1 week using a Mac OS X 10.8.6.

The PMIs in Panel A to C could be predicted by adding the products of the $\log _{2}$ abundance of each gene to its corresponding coefficient. The predicted PMIs for mouse is calculated same way as for zebrafish (shown above). 
Table 3. Mouse probes used to target gene transcripts and their coefficients used to predict PMIs by Panel. The annotations of probes were determined by using NCBI database with 100 bit minimum.

\begin{tabular}{|c|c|c|c|c|c|}
\hline Panel & Organ & Probe & Coefficient & Gene & Gene Name \\
\hline \multirow[t]{7}{*}{ A } & \multirow[t]{7}{*}{ Liver } & A_55_P2007991 & 12.7 & Tuba3b & Tubulin, alpha 3B \\
\hline & & A_51_P227077 & -21.43 & $M d h l b$ & Malate dehydrogenase 1B, NAD (soluble) \\
\hline & & A_55_P2112609 & 14.97 & & Non-coding \\
\hline & & A_30_P01028777 & -1.6 & & Non-coding \\
\hline & & A_51_P318381 & 9.91 & $P g f$ & Placental growth factor \\
\hline & & A_55_P2197847 & 18.41 & & Non-coding \\
\hline & & A_30_P01026843 & 7.59 & Ifitm 2 & $\begin{array}{l}\text { Interferon induced transmembrane protein } \\
2\end{array}$ \\
\hline \multirow[t]{7}{*}{ B } & \multirow[t]{7}{*}{ Brain } & A_52_P627085 & 14.2729 & Mrps $18 c$ & $28 \mathrm{~S}$ ribosomal protein $\mathrm{S} 18 \mathrm{c}$, mitochondrial \\
\hline & & A_30_P01025266 & -59.3569 & Klf14 & Krueppel-like factor 14 \\
\hline & & A_55_P1955891 & -5.57821 & Ppmle & Protein phosphatase 1E \\
\hline & & A_55_P2109107 & 1.92003 & Gra2 & $\begin{array}{l}\text { GDNF family receptor alpha-2 1soform } 3 \\
\text { precursor }\end{array}$ \\
\hline & & A_30_P01031213 & -61.0776 & Acsll & $\begin{array}{l}\text { Long-chain-fatty-acid--CoA ligase } 4 \\
\text { isoform } 1\end{array}$ \\
\hline & & A_52_P418795 & -11.3343 & Grk4 & G protein-coupled receptor kinase 4 \\
\hline & & A_66_P100268 & 59.9399 & & Non-coding \\
\hline \multirow[t]{7}{*}{$\mathrm{C}$} & \multirow[t]{7}{*}{ Brain } & A_30_P01028032 & 9.30294 & Flo11l & Flocculation protein FLO11-like \\
\hline & & A_55_P1972018 & -37.7273 & Histlh4a & Histone $\mathrm{H} 4$ \\
\hline & & A_55_P2410304 & -10.5218 & & Non-coding \\
\hline & & A_52_P1082736 & 15.8909 & Sept1 & Septin-1 \\
\hline & & A_66_P117204 & 9.66267 & $G p c 3$ & Glypican-3 isoform \\
\hline & & A_30_P01020727 & 6.36972 & Adam2 & $\begin{array}{l}\text { Disintegrin and metalloprotease domain } 4 \mathrm{~b} \\
\text { precursor }\end{array}$ \\
\hline & & A_52_P236705 & 5.9439 & Ripply3 & Protein ripply3 \\
\hline
\end{tabular}

We compared the variability in gene transcript abundances between training and testing data sets for the mouse liver and mouse brain. Transcriptional gene profiles of the gene sets used in Fig 4 Panels A and B are shown in Figs 5 and 6, respectively. While most of the mouse liver gene transcript abundances are similar for the training and testing data sets in Fig 5, many of the mouse brain gene transcript abundances are not similar in Fig 6. A two-tailed T-test of the standard deviations of the gene transcript abundances in the training and testing datasets for the liver and brain samples (Fig 5 versus Fig 6) by postmortem time were significantly different $(\mathrm{P}<0.006)$, with higher standard deviations in the brain samples than the liver. This finding indicates that variability in the gene transcript abundances affects PMI predictability. 


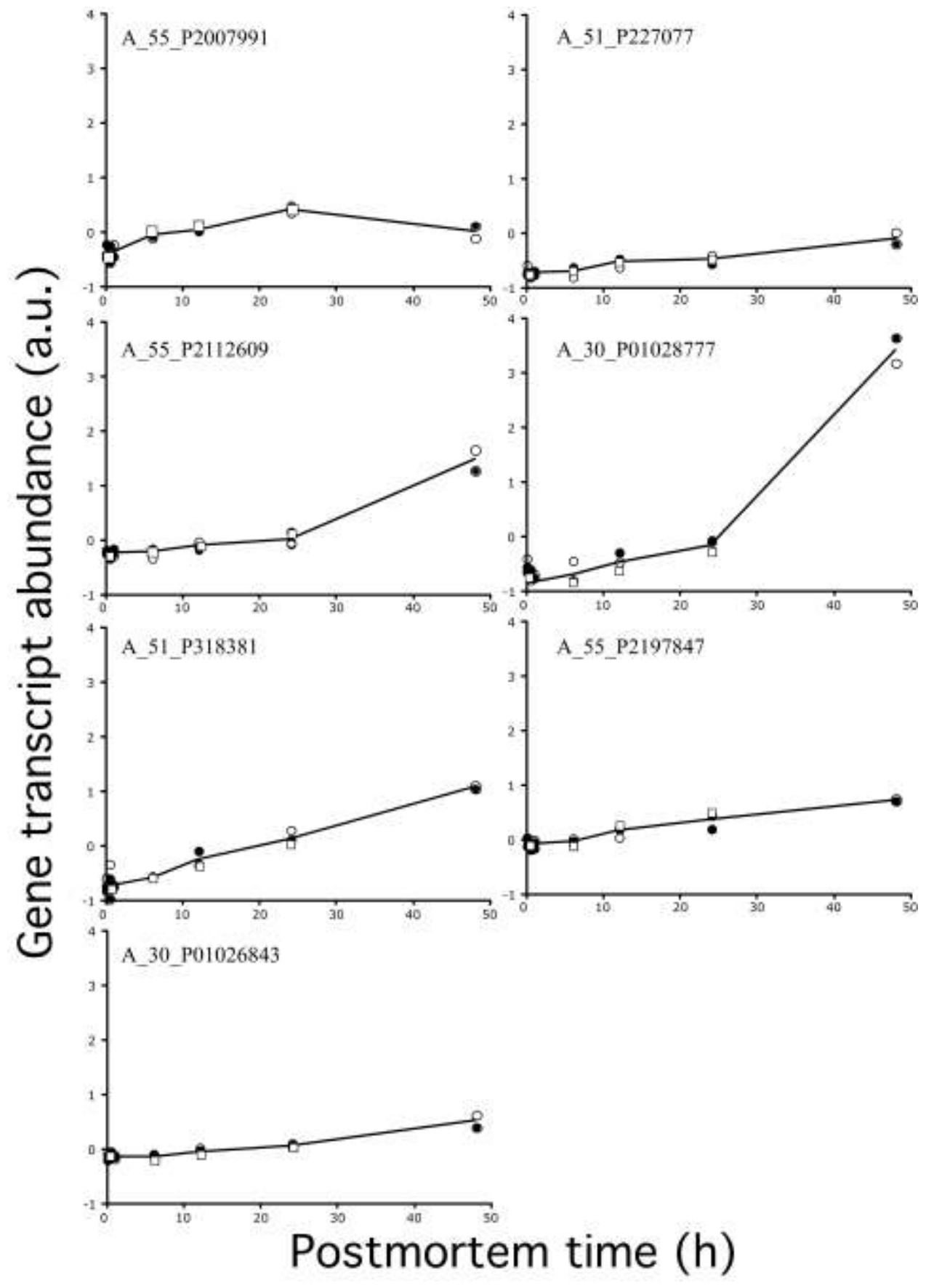

454

Fig 5. Mouse liver transcriptional profiles contributing to Fig 4, Panel A. Open circles, training data; closed circles, testing data; open squares, validation data (not used for training or selection); black line, average. See Table 3 for information on the equations and probe annotations. 


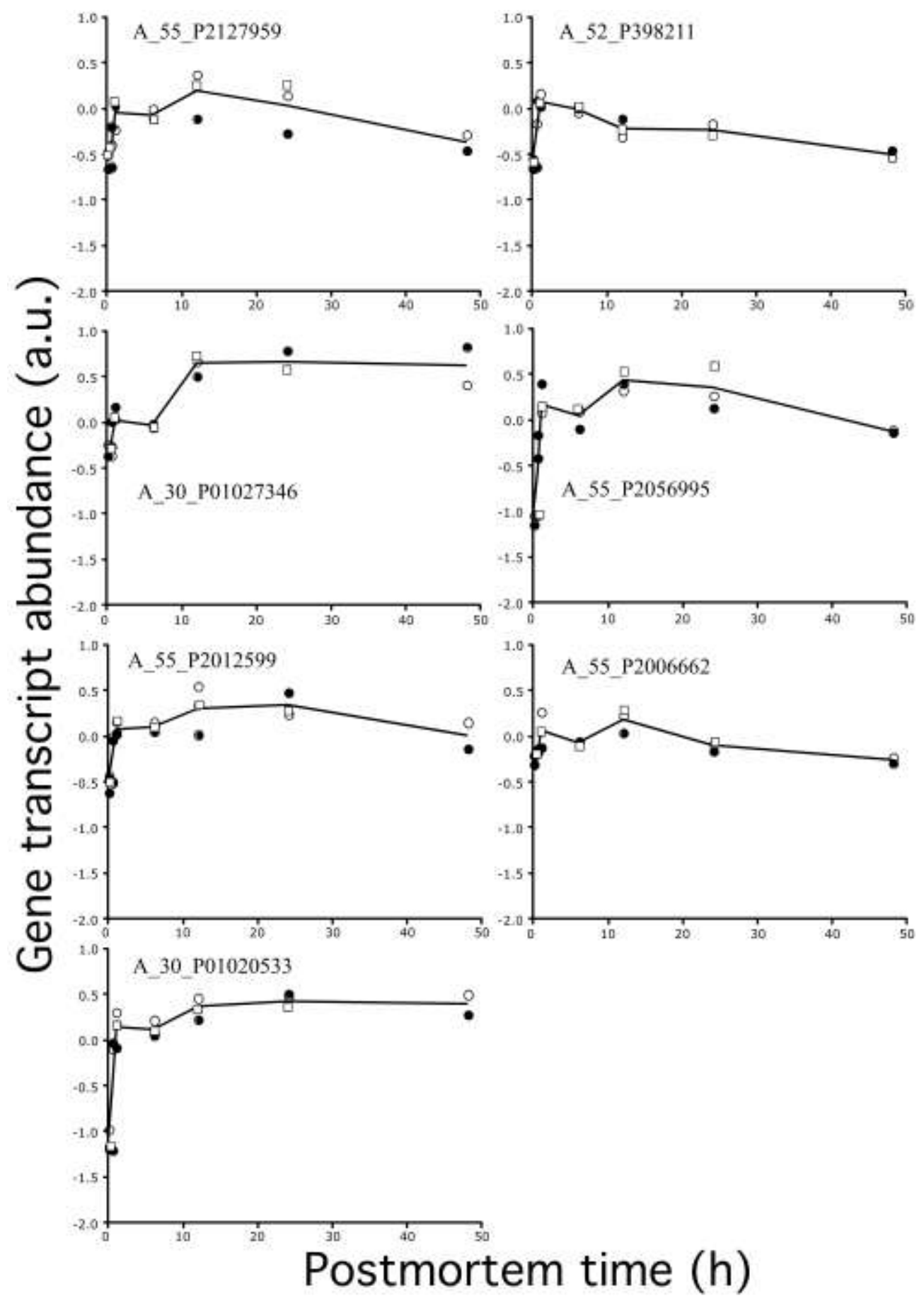

Fig 6. Mouse brain transcriptional profiles contributing to Fig 4, Panel B. Open circles, training data; closed circles, testing data; open squares, validation data; black line, average. See Table 3 for information on the equations and probe annotations.

To further test this phenomenon, a small amount of random noise was added to the abundances of mouse liver gene transcripts (Fig 5), which originally had very low standard deviations by postmortem time. When the introduction of noise approached 
$10 \%$, the fit and slopes were drastically altered (data not shown), indicating that similarity in the gene transcript abundances between the training and test data sets can directly affect the fit and slopes of predicted versus actual PMIs.

\section{Randomization challenge}

Experiments using perfectly-defined linear regressions revealed that $95 \%$ of the training data for the zebrafish and mouse yielded fits $\left(\mathrm{R}^{2}\right)$ and slopes of 1 for predicted versus actual PMIs. To demonstrate that the 'perfect' fits and slopes are functions of the linear regressions, we randomized gene transcript abundances at every postmortem time for all genes in the zebrafish dataset. This randomization maintained the variance in the dataset at each postmortem time so that the variance of the first postmortem time in the randomized dataset was the same as the variance of the gene transcript abundances at the first postmortem time in the original dataset and so on for the gene transcript abundances at all postmortem times.

As anticipated, training of the randomized zebrafish dataset using perfectly-defined linear regressions ( 11 genes by 11 postmortem times x 50,000 repeated gene transcript selections) yielded fits $\left(\mathrm{R}^{2}\right)$ and slopes of 1 for predicted versus actual PMIs for $95 \%$ of the regressions. When we tested the 50,000 regressions using a test dataset, not one of the gene transcript sets approached a fit $\left(\mathrm{R}^{2}\right)$ and slope of 1 . In fact, most yielded slopes of zero and $\mathrm{R}^{2}<0.80$. The significance of this experiment is twofold: (i) it confirms that 'perfect' fits and slopes using the training datasets are a function of 'perfectly-defined' linear regressions, and (ii) it confirms the need to validate the regression equations using testing and validation datasets.

\section{Discussion}

In addition to the different stages of body decomposition (i.e., rigor mortis, livor mortis, algor mortis and putrefaction) [21,22,23], there are many biochemical, biological, chemical, and physical ways to determine PMI. Biochemical indicators and corresponding sample sites include: $\mathrm{pH}$ and spectrophotometer readings of blood and serum [24], cardiac troponin-I and cadaveric blood in the heart [24,25], lactate and malate dehydrogenase in the liver [26], melatonin in the brain, sera, and urine [27], DNA degradation in many tissues and organs $[28,29,30,31]$, endothelial growth factors in the 
brain, heart, liver, and kidneys [32], insulin and glucagonin in pancreatic beta cells [33,34], cells in the cerebrospinal fluid [35], apoptotic cells in skin bruises [36] and histology of labial muscosa [37]. Biological indicators and sample sites include: ciliary motility in the nose [38], sweat gland morphology in the arm pit [39], muscle contraction [40] and pyrosequencing of the buccal cavity, rectum and GI tract samples [41], entomological $[42,43,44]$ and botanical processes occurring in and around the body $[45,46]$. Chemical indicators and sample sites include: electrolytes in human vitreous humour [47], biomarkers (e.g. amino acids, neurotransmitters) in body organs and muscles [48], hypoxanthine in the vitreous humour or cerebrospinal fluid $[49,50,51]$ and potassium in the vitreous humour [52,53,54]. Physical indicators and sample sites include: microwave probe to the skin [55], infrared tympanic thermography and temperature of the ear [56,57], and temperature of the eye and body core $[58,59,60]$. Several formulae have also been developed to estimate PMI that are based on multiple environmental and physicochemical conditions [e.g., 61]. Despite these many approaches, accurate PMI prediction remains an enigma [48]. The motivation for this study was to test experimental designs that could accurately predict PMI using upregulated gene expression data in order to provide "proof of principle".

The abundance of a gene transcript is determined by its rate of synthesis and its rate of degradation [62]. In this study, we presumed that the synthesis of mRNA had to far exceed its degradation to significantly increase gene transcript abundance over the controls (at some postmortem time) in our study. As demonstrated in the previous study [18] and shown in this study (Figs 3, 5, and 6), the timings of the increased abundances differed between genes. Some gene transcripts, such as the one targeted by probe A_15_P105218, increased in abundance right after organismal death and reached maximium abundance at $24 \mathrm{~h}$ postmortem while, others, such as the one targeted by probe A_15_P569742, increased substantially at $48 \mathrm{~h}$ postmortem (Fig 3). It is presumed that differences in the transcript profiles affect the value of the coefficients in the linear equations because it is not possible to generate coefficients for gene transcript abundances that change in the same way. That is, a numerical solution could not be mathematically resolved. 
526 It should be noted that the increased transcript abundance of postmortem genes is optimal

527 for PMI prediction because only about $1 \%$ of the total genes of an organism displayed

528 this phenomenon in organismal death - which is rare indeed. In contrast, a focus on

529 downregulated genes would not be practical because one does not know if downregulated

530 genes are due to repression, degradation of the total RNA, or exhausted resources such as

531 those needed for the transcript machinery function (e.g., dNTPs and RNA polymerase).

532 Given that gene transcripts from the liver were better at PMI predictions than those from

533 the brain suggests that mRNA transcripts from some organs are better than others for

534 these type of analyses. It is conceivable that postmortem genes that significantly increase

535 in abundance could be found in the heart, kidney, spleen or muscle, which needs further

536 exploration.

537 In addition to determining the PMI, the same approach could be implemented for

538 prospective studies aimed at improving organ quality of human transplants. Specifically,

539 similar changes in gene transcript abundances are expected to occur in organ transplants

540 (e.g., liver transplants). Hence, one could design methodology for assessing the

541 suitability of an organ to be transplanted into a recipient before it is transplanted. This

542 might be particularly important to organ recipients because, as our previous study

543 showed, many of the gene transcripts that increased in abundance in organismal death

544 were associated with cancer [18], with the number of cancer genes increasing with

545 postmortem time. This could mean that postmortem time increases the incidence of

546 cancer in the recipient.

547 It is important to recognize that this study would probably not be possible using

548 conventional microarray approaches because normalizations could yield up to 20 to $30 \%$

549 differences in the up- or down-regulation depending on the procedure selected [63-65].

550 The Gene Meter approach does not require the data to be normalized since the microarray

551 probes are calibrated. Moreover, in the processing of samples, the same amount of

552 labeled mRNA was loaded onto the DNA microarray for each sample (1.65 $\mu \mathrm{g})$, which

553 eliminates the need to divide the microarray output data by a denominator in order to

554 compare samples. 
We recognize that our experimental design did not consider factors such as temperature, which have been considered in other models [e.g., 4]. To do so would go beyond the stated objectives of providing a "proof of principle" for the optimal experimental design (i.e., perfectly-defined linear regressions based on multiple gene transcripts) using a high throughput approach. Nonetheless, future studies could make our experimental design more universal by integrating temperature and other factors into the regression models.

In addition to providing "proof of principle" of a new forensic tool for determining PMI, the approach could be used as a tool for prospective studies aimed at improving organ quality of human transplants.

\section{Conclusion}

We examined if gene transcripts with significantly increased abundance could be used to predict PMIs in two model organisms using linear regression analyses. While PMIs could be accurately predicted using selected zebrafish and mouse liver gene transcripts, predictions were poor using selected mouse brain gene transcripts, presumably due to high variability of the biological replicates. The experimental design of selecting groups of gene transcripts, extracting the coefficients with linear regression analyses, testing the regression equations with testing data and validating them using validation data (not used for training or selection), yielded highly accurate PMI predictions. This study warrants the implementation of our experimental design towards the development of an accurate PMI prediction tool for cadavers and possibly a new tool for prospective studies aimed at improving organ quality of human transplants.

\section{Financial disclosure}

The work was supported by funds from the Max-Planck-Society.

\section{Supplemental Information}

\section{Primer on Matrix Algebra}

Our PMI prediction approach using a perfectly defined system relies on matrix linear algebra. The following is an explanation of matrix linear algebra and how it was used in our study to predict PMI with gene expression profiles. A matrix is defined as a rectangular array of related values. These values, which are called elements, usually are 
scalars. Scalars are numbers that represent physical quantities. Elements in a horizontal line are called rows and elements in a vertical line are columns and the number of rows and columns describe a matrix. A matrix, $\mathbf{S}$, with $y$ number of rows and $z$ number of columns is denoted as a $y \mathrm{x} z$ matrix. This matrix can also be notated with subscripts and appears as $\mathbf{S}_{\mathrm{y}, \mathrm{z}}$. Mathematical operations can be performed using matrices, including multiplication. Matrices can be multiplied by one another if one matrix has as many columns as the other matrix has rows. We used linear equations to obtain a matrix product. The number of gene transcripts used in a selected gene transcript set was limited by the number of postmortem sample times.

\section{Example:}

If we arrange individual genes with their transcript abundances at specific postmortem times in columns then, essentially, we have a matrix $\mathbf{A}$ where the columns are the transcriptional profiles for individual genes. Furthermore, we can construct another matrix, $\mathbf{B}$, which defines the data in a different way. In this matrix the values are the actual postmortem sampling times that are ordered in the same way as the abundances of individual gene transcripts. Finally, we can define another matrix, consisting of one column of coefficient values. These are the weighing factors that we will determine using the rules of linear matrix algebra. To deconvolute the transcriptional profiles from the mixtures and solve for the weighing factors, we set up the matrices like so: $\mathbf{A} \times \mathbf{C}=$ B. When this is done we are left with several equations. To solve for $x$ and $y$ we need to follow the rules of linear matrix algebra. First, we must transpose $\mathbf{A}$, which becomes $\mathbf{A}^{\mathrm{T}}$, then multiply both sides of the equation $\mathbf{A} \times \mathbf{B}=\mathbf{C}$ with $\mathbf{A}^{\mathrm{T}}$. Next, we are required to invert the matrix product of $\mathbf{A}^{\mathrm{T}} \mathbf{x} \mathbf{A}$, thus $\mathbf{A}$ becomes $\mathbf{A}^{-1}$ and also multiply both sides of our original equation $\mathbf{A} \times \mathbf{C}=\mathbf{B}$. Our modified equation, which looks like this $\left(\mathbf{A}^{\mathrm{T}} * \mathbf{A}\right)^{-}$ ${ }^{1} \mathbf{A}^{\mathrm{T}} * \mathbf{A} * \mathbf{C}=\left(\mathbf{A}^{\mathrm{T}} * \mathbf{A}\right)^{-1} * \mathbf{A}^{\mathrm{T}} * \mathbf{B}$, is now ready to be solved for $x$ and $y$ in matrix $\mathbf{C}$. Solving for $\mathbf{C}$, we get $\mathbf{C}=\left(\mathbf{A}^{\mathrm{T}} * \mathbf{A}\right)^{-1} * \mathbf{A}^{\mathrm{T}} * \mathbf{B}$. Now the values in the matrix $\mathbf{C}$ are $x$ and $y$. Next, we plug our values for $x$ and $y$ into our matrix equations to obtain predicted (calculated) PMI values. To ascertain whether the predicted PMIs from our group of gene transcripts is accurate, we plotted the actual and predicted PMIs and determined the slope and fit of the regression line. The $\mathrm{R}^{2}$ and the slope of the line was observed to determine how well a group of gene transcripts predicted PMI. The $\mathrm{R}^{2}$ is the measure of 
615 how much variability is accounted for by the model. For example, if the $\mathrm{R}^{2}$ is 0.95 , then

616 the model accounts for $95 \%$ of the variability. The other $5 \%$ is due to undetermined

617 phenomena.

618

619

620

621

622

623

624

625

626

627

628

629

630

631

632

633

634

635

636

637

638

639

640

641

642

643

644

645

646

647

648

649

650

651

652

653

\section{Literature Cited}

1. Anderson, B. Five notorious, homicidal tales of life insurance fraud Real-life clients from hell. LifeHealthPro. Published October 25, 2013 http://www.lifehealthpro.com/2013/10/25/5-notorious-homicidal-tales-of-lifeinsurance-frau

2. Ferreira M. T. and Cunha E. Can we infer post mortem interval on the basis of decomposition rate? A case from a Portuguese cemetery, Forensic Science International 2013;298: e1-298.e6.

3. Sampaio-Silva F, Magalhães T, Carvalho F, Dinis-Oliveira RJ, Silvestre R. Profiling of RNA degradation for estimation of post mortem interval. PLoS One. 2013; 8: e56507.

4. Ma J, Pan H, Zeng Y, Lv Y, Zhang H, Xue A, Jiang J, Ma K, Chen L. Exploration of the R code-based mathematical model for PMI estimation using profiling of RNA degradation in rat brain tissue at different temperatures. Forensic Sci Med Pathol. 2015;11: 530-7.

5. Lv YH, Ma KJ, Zhang H, He M, Zhang P, Shen YW, Jiang N, Ma D, Chen L. A time course study demonstrating mRNA, microRNA, 18S rRNA, and U6 snRNA changes to estimate PMI in deceased rat's spleen. J Forensic Sci. 2014, 59: 1286-94.

6. González-Herrera L, Valenzuela A, Marchal JA, Lorente JA, Villanueva E. Studies on RNA integrity and gene expression in human myocardial tissue, pericardial fluid and blood, and its postmortem stability. Forensic Sci Int. 2013; 232: 218-28.

7. Zapico SC, Menéndez ST, Núñez P. Cell death proteins as markers of early postmortem interval. Cell Mol Life Sci. 2014;71: 2957-62.

8. Birdsill AC, Walker DG, Lue L, Sue LI, Beach TG. Postmortem interval effect on RNA and gene expression in human brain tissue. Cell Tissue Bank. 2011;12: 311-8.

9. Pan W, Byrne-Steele M, Wang C, Lu S, Clemmons S, Zahorchak RJ, Han J. DNA polymerase preference determines PCR priming efficiency. BMC Biotechnol. 2014;14:10. doi: 10.1186/1472-6750-14-10.

10. Lee PD, Sladek R, Greenwood CM, Hudson TJ. Control genes and variability: absence of ubiquitous reference transcripts in diverse mammalian expression studies. Genome Res. 2002;12:292-7.

11. Harr B, Schlötterer C, Comparison of algorithms for the analysis of Affymetrix microarray data as evaluated by co-expression of genes in known operons. Nucl Acids Res. 2006; 34: e8. 
12. Tu Y,Stolovitzky G, Klein U. Quantitative noise analysis for gene expression microarray experiments. Proc Natl Acad Sci USA 2002;99: 14031.

13. Pozhitkov AE, Noble PA, Bryk J, Tautz D. A revised design for microarray experiments to account for experimental noise and uncertainty of probe response. PLoS One. 2014;9: e91295.

14. Harrison A., Binder, H. Buhot, A., Burden, C.J., Carlon, E., Gibas, C., Gamble, L.J. Halperin, A., Hooyberghs, J., Kreil, D.P., Levicky, R., Noble, P.A., Ott, A., Pettitt, B.M., Tautz, D., Pozhitkov, AE. Physico-chemical foundations underpinning microarray and next-generation sequencing experiments. Nucl Acids Res. 2013; 41: 2779-96.

15. Amend AS, Seifert KA, Bruns TD. Quantifying microbial communities with 454 pyrosequencing: does read abundance count? Mol Ecol 2010;19: 5555.

16. Hunter M.C., Pozhitkov A.E. and Noble P.A. Microbial signatures of oral dysbiosis, periodontitis and edentulism revealed by Gene Meter methodology. Journal of Microbiological Methods, 2016; 131:85-101 http://dx.doi.org/10.1101/070367

17. Pine PS, Munro SA, Parsons JR, McDaniel J, Lucas AB, Lozach J, Myers TG, Su Q, Jacobs-Helber SM, Salit M. Evaluation of the External RNA Controls Consortium (ERCC) reference material using a modified Latin square design. BMC Biotechnol. 2016 Jun 24;16(1):54. doi: 10.1186/s12896-016-0281-x.

18. Pozhitkov AE, Neme R, Domazet-Loo T, Leroux BG., Soni S, Tautz D and Noble PA. racing the dynamics of gene transcripts after organismal death. Royal Society Open BIology, Accepted December 8, 2016; http://www.biorxiv.org/content/early/2016/06/11/058305.

19. Pozhitkov AE, Nies G, Kleinhenz B, Tautz D, Noble PA. Simultaneous quantification of multiple nucleic acid targets in complex rRNA åmixtures using high density microarrays and nonspecific hybridization as a source of information. J Microbiol Methods. 2008;75: 92-102. doi: 10.1016/j.mimet.2008.05.013.

20. Pozhitkov AE, Bailey KD, Noble PA. Development of a statistically robust quantification method for microorganisms in mixtures using oligonucleotide microarrays. J Microbiol Methods. 2007;70: 292-300.

21. Council of Europe, Strasbourg, 1999. Recommendation No. R (99) 3 on the Harmonization of Medico-Legal Autopsy Rules and Its Explanatory Memorandum. Strasbourg: Council of Europe; 1999.

22. Kolusayın Ö, Koç S. Ölüm, içinde Soysal Z, Çakalır C. Forensic Medicine, Print I, Istanbul University Cerrahpsa School of Medicine's Publication, Istanbul; 1999; 93 152.

23. Nashelsky MB, Lawrence CH. Accuracy of cause of death determination without forensic autopsy examination. Am J Forensic Med Pathol. 2003;24: 313-9.

24. Donaldson AE, Lamont IL. Biochemistry changes that occur after death: potential markers for determining post-mortem interval. PLoS One. 2013;8: e82011.

25. Sabucedo AJ, Furton KG. Estimation of postmortem interval using the protein marker cardiac Troponin I. Forensic Sci Int. 2003;134: 11-16. 
26. Gos T, Raszeja S. Postmortem activity of lactate and malate dehydrogenase in human liver in relation to time after death. Int J Legal Med. 1993;106: 25-29

27. Mikamimi H, Terazawa K, Takatori T, Tokudome S, Tsukamoto T, Haga K. Estimation of time of death by quantification of melatonin in corpses. Int J Legal Med. 1994;107: 42-51.

28. Di Nunno N, Costantinides F, Cina SJ, Rizzardi C, Di Nunno C, Melato M. What is the best sample for determining the early postmortem period by on-the-spot flow cytometry analysis? Am J Forensic Med Pathol. 2002, 23:173-80.

29. Di Nunno N, Costantinides F, Melato M. Determination of the time of death in a homicide-suicide case using flow cytometry. Am J Forensic Med Pathol. 1999;20: 228-31.

30. Di Nunno N, Costantinides F, Bernasconi P, Bottin C, Melato M. Is flow cytometric evaluation of DNA degradation a reliable method to investigate the early postmortem period? Am J Forensic Med Pathol. 1998;19:50-3.

31. Cina SJ. Flow cytometric evaluation of DNA degradation: a predictor of postmortem interval? Am J Forensic Med Pathol. 1994;15: 300-2.

32. Thaik-Oo M, Tanaka E, Tsuchiya T, Kominato Y, Honda K, Yamazaki K, Misawa S. Estimation of postmortem interval from hypoxic inducible levels of vascular endothelial growth factor. J Forensic Sci. 2002;47: 186-9.

33. Wehner F, Wehner HD, Schieffer MC, Subke J. Delimination of time of death by immunohistochemical detection of insulin in pancreatic beta-cells. Forensic Sci Int. 1999; 105: 161-9.

34. Wehner F, Wehner HD, Subke J. Delimitation of the time of death by immunohistochemical detection of glucagon in pancreatic a-cells. Forensic Sci Int. 2002;124: 192-199.

35. Wyler D, Marty W, Bär W. Correlation between the post-mortem cell content of cerebrospinal fluid and time of death. Int J Legal Med.1994;106: 194-199.

36. Sawaguchi T, Jasani B, Kobayashi M, Knight B. Post-mortem analysis of apoptotic changes associated with human skin bruises. Forensic Sci Int. 2000;108: 187-203.

37. Yadav A, Angadi PV, Hallikerimath S. Applicability of histologic post-mortem changes of labial mucosa in estimation of time of death - a preliminary study. Aust $\mathbf{J}$ For Sci. 2012;44: 343-352.

38. Romanelli MC, Gelardi M, Fiorella ML, Tattoli L, Di Vella G, Solarino B. Nasal ciliary motility: a new tool in estimating the time of death. Int J Legal Med. 2012; 126: 427-33.

39. Cingolani M, Osculati A, Tombolini A, Tagliabracci A, Ghimenton C, Ferrara SD. Morphology of sweat glands in determining time of death. Int J Legal Med. 1994;107: 132-140.

40. Warther S, Sehner S, Raupach T, Püschel K, Anders S. Estimation of the time since death: post-mortem contractions of human skeletal muscles following mechanical stimulation (idiomuscular contraction). Int J Legal Med. 2012;126: 399-405. 
41. Hyde ER, Haarmann DP, Lynne AM, Bucheli SR, Petrosino JF. The living dead: bacterial community structure of a cadaver at the onset and end of the bloat stage of decomposition. PLoS One. 2013;8: e77733.

42. Meiklejohn KA, Wallman JF, Dowton M.DNA barcoding identifies all immature life stages of a forensically important flesh fly (Diptera: Sarcophagidae). J Forensic Sci. 2013;58: 184-7.

43. Warren JA, Anderson GS. Effect of fluctuating temperatures on the development of a forensically important blow fly, Protophormia terraenovae (Diptera: Calliphoridae). Environ Entomol. 2013;42: 167-72.

44. Vasconcelos SD, Soares TF, Costa DL. Multiple colonization of a cadaver by insects in an indoor environment: first record of Fannia trimaculata (Diptera: Fanniidae) and Peckia (Peckia) chrysostoma (Sarcophagidae) as colonizers of a human corpse. Int J Legal Med. 2014;128: 229-33.

45. Cardoso HF, Santos A, Dias R, Garcia C, Pinto M, Sérgio C, Magalhães T. Establishing a minimum postmortem interval of human remains in an advanced state of skeletonization using the growth rate of bryophytes and plant roots. Int J Legal Med. 2010;124: 451-6.

46. Lancia M, Conforti F, Aleffi M, Caccianiga M, Bacci M, Rossi R. The use of Leptodyctium riparium (Hedw.) Warnst in the estimation of minimum postmortem interval. J Forensic Sci. 2013;58 Suppl 1: S239-42.

47. Bocaz-Beneventi G, Tagliaro F, Bortolotti F, Manetto G, Havel J. Capillary zone electrophoresis and artificial neural networks for estimation of the post-mortem interval (PMI) using electrolytes measurements in human vitreous humour. Int J Legal Med. 2002;116: 5-11.

48. Vass AA. The elusive universal post-mortem interval formula. Forensic Sci Int. 2011; 204: 34-40.

49. Madea B, Herrmann N, Henbge C. Precision of estimating the time since death by vitreous potassium--comparison of two different equations. Forensic Sci Int. 1990; 46: 277-84.

50. Madea B, Käferstein H, Hermann N, Sticht G. Hypoxanthine in vitreous humor and cerebrospinal fluid--a marker of postmortem interval and prolonged (vital) hypoxia? Remarks also on hypoxanthine in SIDS. Forensic Sci Int. 1994;65: 19-31.

51. MadeaB. Importance of supravitality in forensic medicine. Forensic Sci Int. 1994; 69: 221-41.

52. Lange N, Swearer S, Sturner WQ. Human postmortem interval estimation from vitreous potassium: an analysis of original data from six different studies. Forensic Sci Int. 1994;66: 159-74.

53. Zhou B, Zhang L, Zhang G, Zhang X, Jiang X. The determination of potassium concentration in vitreous humor by low pressure ion chromatography and its application in the estimation of postmortem interval. J Chromatogr B Analyt Technol Biomed Life Sci. 2007;852: 278-81.

54. Lendoiro E, Cordeiro C, Rodríguez-Calvo MS, Vieira DN, Suárez-Peñaranda JM, López-Rivadulla M, Muñoz-Barús JI. Applications of Tandem Mass Spectrometry 
(LC-MSMS) in estimating the post-mortem interval using the biochemistry of the vitreous humour. Forensic Sci Int. 2012;223: 160-4.

55. Al-Alousi LM, Anderson RA, Land DV. A non-invasive method for postmortem temperature measurements using a microwave probe. Forensic Sci Int. 1994;64: 3546.

56. Cattaneo C, Di Giancamillo A, Campari O, Orthmann N, Martrille L, Domeneghini $\mathrm{C}$, Jouineau C, Baccino E. Infrared tympanic thermography as a substitute for a probe in the evaluation of ear temperature for post-mortem interval determination: a pilot study. J Forensic Leg Med. 2009;16: 215-7.

57. Baccino E, De Saint Martin L, Schuliar Y, Guilloteau P, Le Rhun M, Morin JF, Leglise D, Amice J. Outer ear temperature and time of death. Forensic Sci Int. 1996;83: 133-46.

58. Kaliszan M. Studies on time of death estimation in the early post mortem period -application of a method based on eyeball temperature measurement to human bodies. Leg Med (Tokyo). 2013;15: 278-82.

59. Nelson EL. Estimation of short-term postmortem interval utilizing core body temperature: a new algorithm. Forensic Sci Int. 2000;109: 31-8.

60. Muggenthaler H, Sinicina I, Hubig M, Mall G. Database of post-mortem rectal cooling cases under strictly controlled conditions: a useful tool in death time estimation. Int J Legal Med. 2012;126: 79-87.

61. Megyesi MS, Nawrocki SP, Haskell NH. Using accumulated degree-days to estimate the postmortem interval from decomposed human remains. J Forensic Sci. 2005;50: 618-26.

62. Neymotin, Athanasiadou R, Gresham D. Determination of in vivo RNA kinetics using RATE-seq. RNA. 2014;20: 1645.

63. Barash Y, Dehan E, Krupsky M, Franklin W, Geraci M, Friedman N, Kaminski N. Comparative analysis of algorithms for signal quantitation from oligonucleotide microarrays. Bioinform. 2004, 20: 839.

64. Seo J, Bakay M, Chen YW, Hilmer S, Shneiderman B, Hoffman EP. Interactively optimizing signal-to-noise ratios in expression profiling: project-specific algorithm selection and detection p-value weighting in Affymetrix microarrays. Bioinform. 2004, 20: 2534.

65. Millenaar FF, Okyere J, May ST, van Zanten M, Voesenek LA, Peeters AJ. How to decide? Different methods of calculating gene expression from short oligonucleotide array data will give different results. BMC Bioinform. 2006, 7: 137. 